\title{
The Importance of Four Skills Reading, Speaking, Writing, Listening in a Lesson Hour
}

\author{
PhD Cand. Lorena Manaj Sadiku
}

Aleksander Xhuvani University Elbasan Albania

Abstract

Teaching and learning are two basic processes underlying the activity of students and teachers nowadays. Learning process puts both parties toward each other, what it teaches, and what it takes, the teacher and the student. Today takes great importance to the training of students to teach themselves, their education, equipping them with the skills of independent work with the most advanced methods of learning conscious, sustainable, active and creative. The purpose of this topic is to know the importance of usage of all skills during a lesson hour. The teacher is free to use a variety of methods and strategies of teaching / learning to suit the needs of students in different classes. He combines these methods during the learning process and adapts according to the increasing development of linguistic competence and independence of student development, the consistency of this process. Teaching has at its center the method of communication, task -based methods, functional methods and situations as real life etc. These methods are realized through various strategies and techniques, according to language skills (listening, speaking, reading, writing). Teacher and students collaborate on the organization of teaching / learning. To facilitate the teaching / learning, the teacher finds efficient ways to organize communication activities, provides and suggests source materials for students. In contemporary teaching teacher does not only play the role of teachers, but also plays the role of supervisor. Together they establish cooperative relations in the process of learning. The teacher clarifies the students and takes their understanding of what happens in the classroom. This means clarifying the rules of the line of work and responsibilities of students in the process of activities. The teacher suggests and provides the use of audiovisual means , electronic, and helps students to use various forms of information technology within and outside the classroom . It gives students the website in accordance with the age and educational requirements. On a teaching hour should be applied all four language skills strategies, but they escalate from level to level depending on the objectives. Setting the students in the spotlight makes the student actively participate in linguistic interaction, preparing it for a new phase of his education or of being able to face the demands of the labor market.

Keywords: Reading, writing, listening, speaking

Any language is difficult and easy. Language serves many purposes. Absence of language is mere dearth of communication. The role that language plays is immense, since time embarked. Identified as the need of the hour, the four necessities in language or commonly known as the four skills- Reading, writing, listening and speaking plays a vital role in any language learning quest... The four skills are the pinnacles of language which will take you to greater heights. They are separate yet bound together with an inseparable bond.

Teachers should set high standards for an ESL classroom. They should work to create the necessary condition for students to learn effectively and reach the desired outcome. For the teaching of English to be successful, the four skills, reading, listening, speaking and writing, should be integrated in an effective way. These skills should be addressed in a way that helps students meet the standards you set for them and develop their communicative competence gradually. This encompasses : Listening and speaking: these two skills are highly interrelated and work simultaneously in real life situations. So, the integration of the two aims at fostering effective oral communication. This integration will assure real-life and purposeful communication. Reading and writing: they form a strong relationship with each other as skills. They are tools for achieving an effective written communication. Students need opportunities to develop their reading and writing skills. Developing students' competencies in reading and writing requires exposing students to gradually challenging reading materials and writing tasks. The aim is making students read and write effectively.

In fact, the integration of listening and speaking with reading and writing will make learners good listeners, speakers, readers and writers so as to be able to communicate effectively. The mastery of these skills is a gradual process. Teachers, for instance, should expose learners to gradually challenging tasks and material.

When a teacher makes use of activities that have been specially designed to incorporate several language skills simultaneously (such as reading, writing, listening, and writing), they provide their students with situations that allow for well-rounded development and progress in all areas of language learning. In her reflection, Anna refers to activities that make use of 'the four skills' but she is not quite sure how to plan activities that incorporate all four. In this section we will 
discuss the 'four skills' as well some activities that can be used in the classroom to promote all four. Through daily activities, teachers provide learners with opportunities to develop each skill: students listen (to the teacher use the target language, to a song, to one another in a pair activity), speak (pronunciation practice, greetings, dialogue creation or recitation, songs, substitution drills, oral speed reading, role play), read (instructions, written grammar drills, cards for playing games, flashcards) and write (fill-in-the-blank sheets, sentences that describe a feeling, sight or experience, a dialogue script, a journal entry).

This approach, however, does not combine the four skills so that they can be used together to reach the same end (i. e. language development that is well-rounded).

Two activities that make use of all four skills in tandem are Self-introduction and Reading and Retell. Self-introduction takes the answers to a series of personal questions (name, age, grade level, where you live, members of your family, favourite sports, animals, colours, subjects, etc. ) and sequences them into a self introduction. Students are given large visuals to trigger each component of the self introduction. The teacher can point to each picture while modeling a self-introduction (students are listening) and then invite learners to introduce themselves (speaking) to one or two if their peers. Some of the visuals can then be changed and the students can be invited to introduce themselves to others in the class to whom they have never spoken. This activity can be adapted to become a regular (daily, weekly) warm-up activity to get learners talking in the target language. Having covered listening and speaking in the oral self-introduction, a scenario can then be created wherein learners must write a self-introduction to a potential home stay host. The same picture cues can be used, reconfigured to show a salutation, closing and signature. The picture cues provide learners with support without giving them a text to memorize.

multilevel SL classes, graded readers can be excellent springboards for another activity that integrates the four skills-a reading and retell. First, learners select a book or story at their own level and read it. Learners are then given a template to follow to summarize their thoughts about the story (writing). The summary is designed to help learners gauge the amount of detail required in a retell. After additional practice reading the summary silently and aloud several times, learners are asked to select two or three illustrations from the book to help them tell the story. They then practice telling the story by using the pictures and remembering what they wrote in the template. Students find a partner who has not read the same story and retell (speaking) their story to one another using the selected illustrations. Partners not only listen to the retell but also complete a feedback checklist (writing) about the retell. After reading the feedback, partners switch roles.

\section{Why are four skills activities useful?}

Four skills activities in the language classroom serve many valuable purposes: they give learners scaffolded support, opportunities to create, contexts in which to use the language for exchanges of real information, evidence of their own ability (proof of learning) and, most important, confidence.

Reading is fun-way to knowledge hunt. We read or see innumerable quotes and proverbs on reading. How far is it true? It is true indeed- reading brings wisdom. Through reading, we learn a lot and it is the most prominent language skill. But the fact of making a reading habit or being good at it is the question here. For now, students, adults and even educators read very less. It is a well-known fact that when there were no televisions or computers or other forms of entertainment, reading was a primary leisure activity among the educated lot. People would spend hours reading books and travel to lands far away or enjoy love, cherish victorious moments and live history-in their minds. The tragedy is that, with time, people have lost their skill and passion to read. Reading has declined among every group of people in today's world of technology and entertainment. There are many other exciting and thrilling options available, aside from books. And that is a shame because reading offers a productive approach to improving language- vocabulary and word power for example. When you possess rich vocabulary, you listen better as you understand more; then you can write better with more words to choose from; obviously you can speak better because of your intense word power. It is advisable to indulge in at least half an hour of reading a day to keep abreast of the various styles of writing and new vocabulary. Thus, the need to develop a habit to read is very important. Well, the skills will hopefully jump in automatically once the strong genuine habit has been established. The best and easiest approach is however, to make a small effort to read a piece a day... you will surely succeed. 
Writing is a gem to pick. A person with good writing skills is always victorious at expressing oneself. The writing skill is the 'hard copy' of your intellectual level or the level of your expression. The writing process is taught in schools and colleges. But, do you practice it in reality? Or Do you start to write as soon as the question is read. Pre Writing opens the doors to effective writing where you brainstorm almost anything under the topic or theme. You find a topic, narrow it, and consider the purpose, audience as well as the form of writing. You are not concerned with creating whole sentences or paragraphs at this point rather you should aim at defining an idea and getting it rolling. Then we write our first draft which is a compilation of our random thoughts. This is where our words form sentences and paragraphs. The third step is revision. Revision means "Seeing again. " Here you refine the ideas in their compositions. Revising consists of three activities: rereading the rough draft, sharing the rough draft in a writing group/with anyone, and revising on basis of feedback. You can add or substitute thoughts and words. The same can be done with deleting and moving your words in the draft. Editing is the next big thing. The cleaning up process where the clutter is cleared and ideas are allowed to shine happens here. We tend to putting the piece of writing into its final form and you fine-tune your work by focusing on correct punctuation, capitalization, grammar, usage, and paragraphing. The goal here is to make the writing 'optimally readable. "The last is publishing you final piece. Each step is interchangeable and can be done as many as you dare or till your writing perfects. I always tell my students to work out at least three drafts. So this is it with writing...easy? It would turn out simply simple if you make it a habit and practice like you practice your favourite song or dance. Tip: Avoid electronic English ( $u$ for you)

Listening is yet another necessitate in language. The more efficient a listener you are... the more successful and satisfied you will be. Listening...is not merely hearing: it is a state of receptivity that permits understanding of what is heard and grants the listener full partnership in the communication process. We need to develop a keen interest in making ourselves better ears. The fact that we listen more than our ears and we listen far more than the sound is very true. As any member in a society, listening is one important skill to possess as good listening is an integral part of communication process. A good listener shows readiness and possesses an ability to manipulate the sound into words and their contextual meaning. Then the good listener relates given meanings to other experiences and he shares responsibility with the speaker. Academically, listening skills plays a vital role in the teaching-learning cycle. A student learns better when he can listen better. A teacher is also in need of a good listening skill. All the way, listening should be enhanced in your life as to be a greater speaker. The attitude of the listener is another stepping stone to achieve this skill.

Speaking is all special. This skill is as important as the others. When you have words read, ideas written and thoughts heard, all you need is to express- your speaking skill. What you speak will determine the expressiveness in you. Speaking has many masks- public, friendly or academic contexts are few from the lot. Each context has the same need for the skill. Statistics reveal that when you talk, you use about five syllables per second and there are more than forty different speech sounds. Thus, every time you talk, your audience must catch all the five syllables per second out of the air, must recognize the forty sounds in them, must translate the syllables into words and finally they must translate the words into thoughtsyou got to help them succeed in doing so. If you slur or muffle sounds, or project the sounds weakly, the listener will miss a lot, failing you as a good speaker. Therefore, proper pronunciation, diction and building a good vocabulary should be on your prioritized list. Tip: Avoid one word answers or queries.

As a student, the skills of language will make you academically sound and the miracle it will have when you enter the world as an adult is magical in an adventure. Mind you, the four skills never stand out as individual areas but they form a chain cycle, where you break one ring of the chain and the whole chain would collapse. In the changing competitive world, your command over a language and even more the level of your English can determine your life.

Thus, it is so much imperative for you to understand the four skills and give it a consistent effort. The result will be astonishing! 